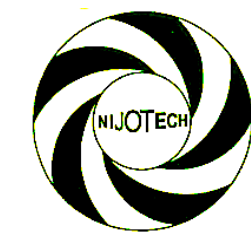

Nigerian Journal of Technology (NIJOTECH)

Vol. 39, No. 1, January 2020, pp. 148 - 153

Copyright@ Faculty of Engineering, University of Nigeria, Nsukka, Print ISSN: 0331-8443, Electronic ISSN: 2467-8821

www.nijotech.com

http://dx.doi.org/10.4314/njt.v39i1.16

\title{
PRESSURE BEHAVIOUR OF A HORIZONTAL WELL SANDWICHED BETWEEN TWO PARALLEL SEALING FAULTS
}

\author{
A. V. Ogbamikhumi ${ }^{1, *}$ and E. S. Adewole ${ }^{2}$ \\ 1, 2, Department of Petroleum Engineering, University of Benin, Benin City, Edo State, Nigeria \\ E-mail addresses; ${ }^{1}$ aiankhovictor@gmail.com, ${ }^{2}$ steve.adewole@yahoo.com
}

\begin{abstract}
Generally, reservoir fluid flow is governed by diffusivity equation and solution to this equation helps to investigate pressure behaviour under certain reservoir and wellbore boundary conditions. In this paper however, the analytical solution method of Green and Source function is deployed to determine the performance of a horizontal well located between two parallel sealing faults, assuming simple rectangular reservoir geometry. Also, the dimensionless pressure and derivative approach is applied for all computations as it prevents the problem of unit conversions, reduces longer expressions and it helps to handle numerical values. The pressure expression derived from this work reveals that a maximum of two flow periods occur for the stated reservoir model. It was found out that an inverse relationship exists between dimensionless pressure and dimensionless length while pressure increased with thickness. Also high vertical permeability shortens the effect of the early radial flow period experienced by the horizontal well, thereby increasing productivity index. Finally, it was discovered that increased perforation length reduces the production potential of the horizontal well.
\end{abstract}

Keywords: Dimensionless pressure, pressure derivatives, heterogeneity, pressure performance, reservoir and wellbore characterization.

\section{INTRODUCTION}

On the discovery of a commercially productive reservoir, the reservoir engineer is expected to set up a developmental plan that will aid optimum recovery of hydrocarbon reserves from the field under prevailing economic conditions, government policies and operating methods. Central to this plan are information obtained from detailed analyses of formation/well tests that are required for reservoir characterization, optimum production and determination of future development and production, thereby maximizing profit. Such information which may include average reservoir pressure, nature and extent of the reservoir boundary, heterogeneity, fluid and wellbore properties assist the reservoir specialist to take critical reservoir management decisions. For instance, the presence of faults and/or fractures over the years have continued to play a major role in the exploitation of petroleum from subsurface reservoirs as the identification of these structures through well test analyses provide significant boost to the production output of most developed nations. Since most petroleum-bearing reservoirs are faulted, adequate knowledge on the structure and communication of the fault region can have substantial effect on the economic feasibility of exploration goals and provides useful information for reservoir management. Consequently, understanding the effects of faults on the pressure performance of the petroleum reservoir is desired to enable proper reservoir and wellbore characterization. In this work, analytical solution method involving physical and mathematical models is used to define the possible flow regimes as well as pressure transient of a horizontal well located in a reservoir bounded by parallel sealing faults (no-flow boundaries) at the top and bottom with infinite-acting lateral extremities. Other objectives to be achieved from this reservoir model include the effect of varying well lengths, formation thicknesses, wellbore radius, perforation lengths and permeability distribution on the transient behaviour of the horizontal well in real time.

* Corresponding author, tel: +234 802-581-6927 


\section{ANALYTICAL MODEL DESCRIPTION}

In petroleum engineering, horizontal well flow conforms to the second order, linear, heterogeneous partial differential equation called the diffusivity equation. This equation is usually presented in 3-D and is given by [1].

$$
\mathrm{K}_{\mathrm{x}} \frac{\partial^{2} \mathrm{P}}{\partial \mathrm{x}^{2}}+\mathrm{K}_{\mathrm{y}} \frac{\partial^{2} \mathrm{P}}{\partial \mathrm{y}^{2}}+\mathrm{K}_{\mathrm{z}} \frac{\partial^{2} \mathrm{P}}{\partial \mathrm{z}^{2}}=\emptyset \mu \mathrm{C}_{\mathrm{t}} \frac{\partial \mathrm{P}}{\partial \mathrm{t}}
$$

However, solution to this equation helps to generate an analytical model that will aid the reservoir engineer to analyze the performance of the particular horizontal well model. The solution technique to be adopted for this paper as mentioned earlier is the Green and Source function solution method.

\subsection{Physical Reservoir Model}

A simple rectangular geometry in fig 1 is selected to represent the reservoir model. The top and bottom boundaries of the model are no-flow boundaries and in the lateral directions, the reservoir is infinite-acting. This kind of reservoir is referred to as a laterally infinite reservoir.

\subsection{Mathematical Solution of the Reservoir Model}

Based on the horizontal model selected, the flow periods that can exist are the mandatory infinite-acting flow regime (called early radial flow) when no boundary has been encountered and the early time linear flow (or intermediate-time linear flow) as flow propagation reaches the vertical no-flow boundaries. Hence, the resulting dimensionless instantaneous source functions based on the available boundaries of the model are as follows:

i. The instantaneous source function in the $x$ direction during the early radial flow regime is that of an infinite slab source in an infinite slab reservoir where the dimensionless equivalent source function is given by ${ }^{[3]}$;

$$
\mathrm{S}\left(\mathrm{x}_{\mathrm{D}}, \mathrm{t}_{\mathrm{D}}\right)=\frac{1}{2}\left\langle\operatorname{erf}\left(\frac{\sqrt{\frac{\mathrm{K}_{\mathrm{H}}}{\mathrm{K}_{\mathrm{x}}}}+\mathrm{x}_{\mathrm{D}}}{2 \sqrt{\mathrm{t}_{\mathrm{D}}}}\right)+\operatorname{erf}\left(\frac{\sqrt{\frac{\mathrm{K}_{\mathrm{H}}}{\mathrm{K}_{\mathrm{x}}}}-\mathrm{x}_{\mathrm{D}}}{2 \sqrt{\mathrm{t}_{\mathrm{D}}}}\right)\right\rangle
$$

The instantaneous source function in the $y$-direction during the early radial flow regime is that of an infinite plane source in an infinite slab reservoir where the dimensionless equivalent source function is expressed as;

$$
\mathrm{S}\left(\mathrm{y}_{\mathrm{D}}, \mathrm{t}_{\mathrm{D}}\right)=\frac{1}{2 \sqrt{\pi \mathrm{t}_{\mathrm{D}}}} \sqrt{\frac{\mathrm{K}_{\mathrm{H}}}{\mathrm{K}_{\mathrm{y}}}} \mathrm{e}^{-\frac{\left(\mathrm{y}_{\mathrm{D}}-\mathrm{y}_{\mathrm{WD}}\right)^{2}}{4 \mathrm{t}_{\mathrm{D}}}}
$$

During the early radial flow, flow in the z-direction is similar to that in the $y$-direction, that is, infinite plane source in an infinite slab reservoir. Therefore, the dimensionless source function is given by;

$$
\mathrm{S}\left(\mathrm{z}_{\mathrm{D}}, \mathrm{t}_{\mathrm{D}}\right)=\frac{1}{2 \sqrt{\pi \mathrm{t}_{\mathrm{D}}}} \sqrt{\frac{\mathrm{K}_{\mathrm{H}}}{\mathrm{K}_{\mathrm{z}}}} \mathrm{e}^{-\frac{\left(\mathrm{z}_{\mathrm{D}}-\mathrm{z}_{\mathrm{wD}}\right)^{2}}{4 \mathrm{t}_{\mathrm{D}}}}
$$

When the vertical no-flow boundaries are encountered, the source functions in $x$ and $y$-axes remains that of infinite slab source and infinite plane source respectively as represented by eqns. (2) and (3). This is because flow in these directions has still not encountered any boundaries; however this is not the same case for flow in the z-direction. Here pressure declines constantly with respect to time due to effect of sealing faults and the expression for instantaneous source function in the z-axis changes to;

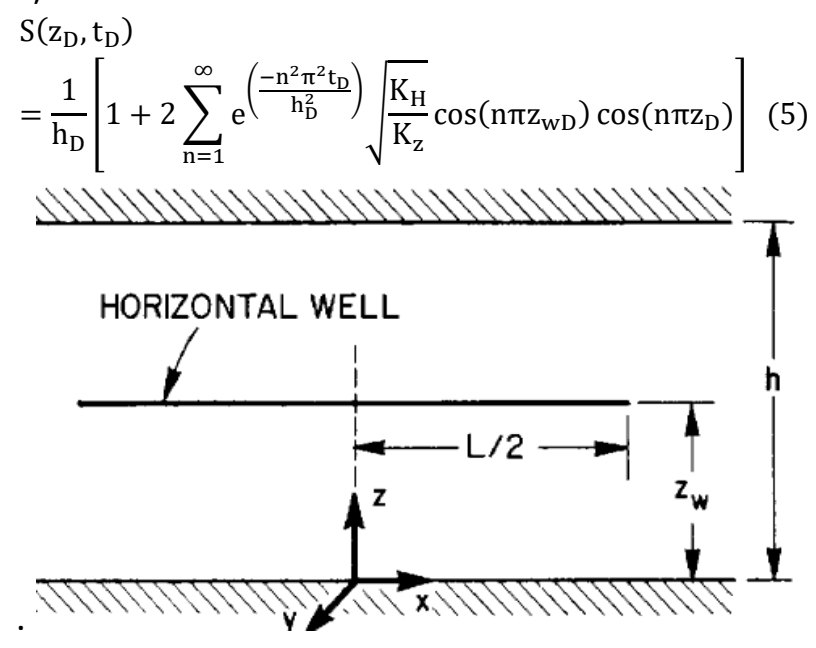

Fig. 1: Laterally Infinite Reservoir [2]

\subsection{Pressure performance equation of the horizontal well model}

When dimensionless approach is adopted to define parameters, then the following expression is used to compute dimensionless pressure:

$$
P_{D}=2 \pi h_{D} \int_{0}^{t_{D}} S\left(x_{D}, y_{D}, z_{D}, \tau\right) d \tau
$$

where $t_{D}=\tau, \quad d_{D}=d \tau$ and $S\left(x_{D}, y_{D}, z_{D}, t_{D}\right)$ is Newman's product [2] of the instantaneous source functions in each dimension such that;

$\mathrm{S}\left(\mathrm{x}_{\mathrm{D}}, \mathrm{y}_{\mathrm{D}}, \mathrm{z}_{\mathrm{D}}, \mathrm{t}_{\mathrm{D}}\right)=\mathrm{S}\left(\mathrm{x}_{\mathrm{D}}, \mathrm{t}_{\mathrm{D}}\right) \times \mathrm{S}\left(\mathrm{y}_{\mathrm{D}}, \mathrm{t}_{\mathrm{D}}\right) \times \mathrm{S}\left(\mathrm{z}_{\mathrm{D}}, \mathrm{t}_{\mathrm{D}}\right)$ Hence for the given physical reservoir model, considering all the flow periods based on the available reservoir boundaries;

$\mathrm{P}_{\mathrm{DT}}=2 \pi \mathrm{h}_{\mathrm{D}} \int_{0}^{\mathrm{t}_{\mathrm{De}}}($ early $\mathrm{x}) \times($ early $\mathrm{y}) \times($ early $\mathrm{z}) \mathrm{d} \tau+$

$2 \pi h_{D} \int_{t_{D e}}^{t_{D 1}}($ early $x)($ early y) $\times($ late $z) d \tau$ 
$t_{D e}$ is obtained using Odeh and Babu flow period equation [4-6];

$$
\mathrm{t}_{\mathrm{De}}=\frac{0.001056 \mathrm{~K}_{\mathrm{v}} \mathrm{t}_{\mathrm{e}}}{\emptyset \mu \mathrm{C}_{\mathrm{t}} \mathrm{L}^{2}}
$$

and

$$
\mathrm{t}_{\mathrm{e}}=\frac{1800 \mathrm{~d}_{\mathrm{z}}^{2} \varnothing \mu \mathrm{C}_{\mathrm{t}}}{\mathrm{K}_{\mathrm{v}}}
$$

or

$$
\mathrm{t}_{\mathrm{e}}=\frac{125 \mathrm{~L}^{2} \emptyset \mu \mathrm{C}_{\mathrm{t}}}{\mathrm{K}_{\mathrm{v}}}
$$

To evaluate $t_{\text {De, }}$, the minimum of eqns. (10) and (11) is therefore applied.

\subsubsection{Early Radial Flow Regime}

This flow period develops when the well is initially opened for production and the flow has not experienced influence of any external boundaries. The flow is radial and is equivalent to that of a fully penetrating vertical well in an infinite-acting reservoir; hence it is also referred to as vertical radial flow regime $e^{[2,4]}$. The dimensionless pressure for this regime designated as $\mathrm{PD}_{\mathrm{D} 1}$ is represented by the first part of eqn.(8), that is

$$
P_{D 1}=2 \pi h_{D} \int_{0}^{t_{D e}} s(x, \tau) \times s(y, \tau) \times s(z, \tau) d \tau
$$

Substituting corresponding source functions of equations (2) to (4), eqn. (12) can be rewritten as follows:

$$
\mathrm{P}_{\mathrm{D} 1}=2 \pi \propto \mathrm{h}_{\mathrm{D}} \int_{0}^{\mathrm{t}_{\mathrm{De}}} \frac{\mathrm{e}^{-\mathrm{u}}}{8 \mathrm{u}} \mathrm{du}
$$

Where $\alpha=1$ for $\mathrm{x}_{\mathrm{D}}=1.0$ (well toe) at early time [2-4]

$$
\begin{gathered}
u=\frac{r_{w D}^{2}}{4 t_{D}} \\
r_{w D}^{2}=\left(y_{D}-y_{w D}\right)^{2}+\left(z_{D}-z_{w D}\right)^{2}
\end{gathered}
$$

The solution to the eqn. (13) is derived as follows

$$
\mathrm{P}_{\mathrm{D} 1}=-\frac{\mathrm{h}_{\mathrm{D}}}{4} \operatorname{Ei}\left(-\frac{\mathrm{r}_{\mathrm{wD}}^{2}}{4 \mathrm{t}_{\mathrm{De}}}\right)
$$

Equation (16) is the dimensionless pressure drop of a horizontal well when it is infinite-acting. That is, when no external boundary has been felt during flow.

\subsubsection{Early Time Linear Flow}

Generally, linear flow usually develops when any of the upper or lower sealed boundaries is encountered. Therefore, as flow progresses beyond the horizontal wellbore and reaches the upper and lower boundaries, intermediate-time linear flow is generated. This flow period which is a transition between the vertical radial flow and the horizontal radial flow (pseudoradial or late time radial flow [7]), is predominant when the well length is sufficiently long compared to the formation thickness. The dimensionless pressure for this regime designated as $\mathrm{PD}_{\mathrm{D} 2}$ is represented by the second part of eqn. (8), written as follows:

$$
\mathrm{P}_{\mathrm{D} 2}=2 \pi \mathrm{h}_{\mathrm{D}} \int_{\mathrm{t}_{\mathrm{De}}}^{\mathrm{t}_{\mathrm{D} 1}}(\text { early } \mathrm{x})(\text { early } \mathrm{y}) \times(\text { late } \mathrm{z}) \mathrm{d} \tau
$$

Inserting the relevant source functions from eqns. (2), (3) and (5) gives

$\mathrm{P}_{\mathrm{D} 2}=2 \pi \mathrm{h}_{\mathrm{D}} \int_{\mathrm{t}_{\mathrm{D}} \mathrm{t}}^{\mathrm{t}_{\mathrm{D}}}\left[\frac{1}{2}\left\langle\operatorname{erf}\left(\frac{\sqrt{\frac{\mathrm{K}_{\mathrm{H}}}{\mathrm{K}_{\mathrm{X}}}}+\mathrm{x}_{\mathrm{D}}}{2 \sqrt{\tau}}\right)+\right.\right.$

$\left.\operatorname{erf}\left(\frac{\sqrt{\frac{K_{\mathrm{H}}}{\mathrm{K}_{\mathrm{K}}}}-\mathrm{x}_{\mathrm{D}}}{2 \sqrt{\tau}}\right)\right\rangle *\left[\frac{1}{2 \sqrt{\pi \tau}} \sqrt{\frac{\mathrm{K}_{\mathrm{H}}}{\mathrm{K}_{\mathrm{y}}}} \mathrm{e}^{-\frac{\left(\mathrm{y}_{\mathrm{D}}-\mathrm{y}_{\mathrm{wD}}\right)^{2}}{4 \tau}}\right] *\left[\frac{1}{\mathrm{~h}_{\mathrm{D}}}(1+\right.$

$\left.\left.2 \sum_{\mathrm{n}=1}^{\infty} \mathrm{e}^{\left(\frac{-\mathrm{n}^{2} \pi^{2} \tau}{\mathrm{h}_{\mathrm{D}}^{2}}\right)} \sqrt{\frac{\mathrm{K}_{\mathrm{H}}}{\mathrm{K}_{\mathrm{z}}}} \cos \left(\mathrm{n} \pi \mathrm{z}_{\mathrm{wD}}\right) \cos \left(\mathrm{n} \pi \mathrm{z}_{\mathrm{D}}\right)\right)\right] \mathrm{d} \tau$

Hence, the total dimensionless pressure from inception of flow to date is written as

$$
\mathrm{P}_{\mathrm{DT}}=\mathrm{P}_{\mathrm{D} 1}+\mathrm{P}_{\mathrm{D} 2}
$$

The exponential integral Ei is obtained from tables or graph of $\mathrm{Ei}$ [9] or eqn. (13) could be evaluated numerically according to Gauss-Laguerre quadrature [10]. The integral in the second part can be integrated according to Gauss-Legendre quadrature.

\subsubsection{Pressure Derivative of Expression}

The total dimensionless pressure derivative is given as

$$
\mathrm{P}_{\mathrm{DT}}^{\prime}=\mathrm{t}_{\mathrm{D}} \times \frac{\partial \mathrm{P}_{\mathrm{DT}}}{\partial \mathrm{t}_{\mathrm{D}}}
$$

Equation (20) is solved by direct substitution of reservoir system parameters for every flow time.

\section{DATA SELECTION FOR CASE STUDY OF THE HORIZONTAL WELL MODEL}

The following theoretical reservoir and well parameters are selected for computation of dimensionless pressures and derivatives for detailed investigation of pressure transient behaviour of the horizontal well model:

$\mathrm{h}=100,250$ and 400fts; $\mathrm{L}=800,1200$ and 2500fts; $\mathrm{K}_{\mathrm{v}} / \mathrm{K}_{\mathrm{H}}=0.10,0.60$ and 1.00 . Also $\mathbf{x}_{\mathbf{D}}=1.0$ (well toe); $\mathrm{y}_{\mathrm{D}}=\mathrm{y}_{\mathrm{wD}}$ (line source well); dimensionless wellbore radius $r_{w D}=z_{D}-z_{w D}=0.1$. The following definitions of the reservoir model are also deployed for computation:

$$
\begin{array}{r}
\mathrm{L}_{\mathrm{D}}=\frac{\mathrm{L}}{2 \mathrm{~h}} \sqrt{\frac{\mathrm{k}_{\mathrm{v}}}{\mathrm{k}_{\mathrm{H}}}} \\
\mathrm{h}_{\mathrm{D}}=\frac{1}{\mathrm{~L}_{\mathrm{D}}}
\end{array}
$$


Table 1: Computed Values of $L_{D}$ and $t_{D e}$

\begin{tabular}{|c|c|c|c|c|c|c|c|c|c|c|c|c|c|c|c|c|c|}
\hline \multirow{3}{*}{$L(\mathrm{ft})$} & \multicolumn{6}{|c|}{$h=100 \mathrm{ft}$} & \multicolumn{6}{|c|}{$h=250 \mathrm{ft}$} & \multicolumn{5}{|c|}{$\mathrm{h}=400 \mathrm{ft}$} \\
\hline & $\mathrm{K}_{\mathrm{v}} /$ & 0.10 & & $=0.60$ & $\mathrm{~K}_{\mathrm{v}} / \mathrm{l}$ & 1.00 & $\mathrm{~K}_{\mathrm{v}} /$ & $=0.10$ & $\mathrm{~K}_{\mathrm{v}} / \mathrm{l}$ & $=0.60$ & & 1.00 & $\mathrm{~K}_{\mathrm{v}} /$ & $=0.10$ & & 0.60 & $\mathrm{~K}_{\mathrm{v}} / \mathrm{K}_{\mathrm{H}}=1.00$ \\
\hline & LD & tDe & LD & tDe & LD & tDe & LD & tDe & LD & tDe & LD & tDe & LD & tDe & LD & tDe & LD \\
\hline
\end{tabular}

$\begin{array}{lllllllllllllllllll}800 & 1.26 & 0.0027 & 3.10 & 0.0027 & 4.00 & 0.0027 & 0.51 & 0.0327 & 1.24 & 0.0327 & 1.60 & 0.0327 & 0.32 & 0.0961 & 0.77 & 0.0961 & 1.00 & 0.0961\end{array}$

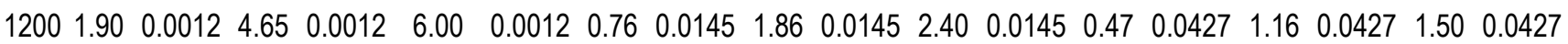

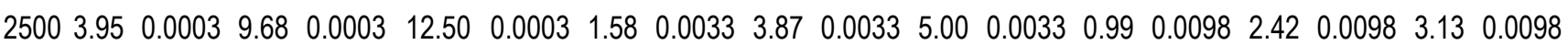

Table 2: Computed Values of $P_{D T}$ and $P^{\prime}$ DT for $L=800 \mathrm{ft}$

\begin{tabular}{|c|c|c|c|c|c|c|c|c|c|c|c|c|c|c|c|c|c|c|}
\hline \multirow[t]{3}{*}{$t_{D 1}$} & \multicolumn{6}{|c|}{$h=100 \mathrm{ft}$} & \multicolumn{6}{|c|}{$\mathrm{h}=250 \mathrm{ft}$} & \multicolumn{6}{|c|}{$h=400 \mathrm{ft}$} \\
\hline & \multicolumn{2}{|c|}{$\overline{K_{v} / K_{H}}=0.10$} & \multicolumn{2}{|c|}{$\mathrm{K}_{\mathrm{V}} / \mathrm{K}_{\mathrm{H}}=0.60$} & \multicolumn{2}{|c|}{$\mathrm{K}_{\mathrm{V}} / \mathrm{K}_{\mathrm{H}}=1.00$} & \multicolumn{2}{|c|}{$\mathrm{K}_{\mathrm{V}} / \mathrm{K}_{\mathrm{H}}=0.10$} & \multicolumn{2}{|c|}{$\mathrm{K}_{\mathrm{v}} / \mathrm{K}_{\mathrm{H}}=0.60$} & \multicolumn{2}{|c|}{$\mathrm{K}_{\mathrm{V}} / \mathrm{K}_{\mathrm{H}}=1.00$} & \multicolumn{2}{|c|}{$\mathrm{K}_{\mathrm{V}} / \mathrm{K}_{\mathrm{H}}=0.10$} & \multicolumn{2}{|c|}{$\mathrm{K}_{\mathrm{V}} / \mathrm{K}_{\mathrm{H}}=0.60$} & \multicolumn{2}{|c|}{$\mathrm{K}_{\mathrm{V}} / \mathrm{K}_{\mathrm{H}}=1.00$} \\
\hline & $\overline{P_{D}}$ & $P^{\prime}{ }^{\prime}$ & $P_{D}$ & $P_{D}^{\prime}$ & $P_{D}$ & $P_{D}^{\prime}$ & $P_{D}$ & $P_{D}^{\prime}$ & $P_{D}$ & $P_{D}^{\prime}$ & $P_{D}$ & $P_{D}^{\prime}$ & $P_{D}$ & $P_{D}^{\prime}$ & $P_{D}$ & $P_{D}^{\prime}$ & $P_{D}$ & $P_{D}^{\prime}$ \\
\hline$\overline{10^{-3}}$ & 0.00 & 0.42 & 0.00 & 0.21 & 0.00 & 0.18 & 0.00 & 1.00 & 0.00 & 0.45 & 0.00 & 0.37 & 0.36 & 1.59 & 0.00 & 0.69 & 0.00 & 0.56 \\
\hline $10^{-2}$ & 0.05 & 0.45 & 0.13 & 0.29 & 0.17 & 0.30 & 0.00 & 1.04 & 0.00 & 0.54 & 0.00 & 0.49 & 0.41 & 1.63 & 0.00 & 0.79 & 0.00 & 0.68 \\
\hline $10^{-1}$ & 0.28 & 0.57 & 0.68 & 0.59 & 0.87 & 0.69 & 0.21 & 1.16 & 0.39 & 0.84 & 0.49 & 0.87 & 0.65 & 1.75 & 0.29 & 1.09 & 0.23 & 1.06 \\
\hline 100 & 0.92 & 0.96 & 2.25 & 1.53 & 2.91 & 1.90 & 0.92 & 1.54 & 2.13 & 1.78 & 2.74 & 2.09 & 1.40 & 2.13 & 2.12 & 2.03 & 2.59 & 2.28 \\
\hline $10^{1}$ & 2.92 & 2.17 & 7.16 & 4.50 & 9.25 & 5.73 & 2.96 & 2.75 & 7.14 & 4.75 & 9.20 & 5.92 & 3.51 & 3.34 & 7.28 & 4.99 & 9.26 & 6.11 \\
\hline $10^{2}$ & 9.25 & 6.00 & 22.70 & 13.90 & 29.30 & 17.80 & 9.30 & 6.59 & 22.70 & 14.10 & 29.30 & 18.00 & 9.88 & 7.18 & 22.90 & 14.40 & 29.40 & 18.20 \\
\hline $10^{3}$ & 29.30 & 18.10 & 71.70 & 43.60 & 92.50 & 56.20 & 29.30 & 18.70 & 71.70 & 43.80 & 92.50 & 56.40 & 29.90 & 19.30 & 71.90 & 44.10 & 92.70 & 56.60 \\
\hline
\end{tabular}

Table 3: Computed Values of $P_{D T}$ and $P_{D T}^{\prime}$ for $L=1200 \mathrm{ft}$.

\begin{tabular}{|c|c|c|c|c|c|c|c|c|c|c|c|c|c|c|c|c|c|c|}
\hline \multirow{3}{*}{ tD1 } & \multicolumn{6}{|c|}{$h=100 \mathrm{ft}$} & \multicolumn{6}{|c|}{$\mathrm{h}=250 \mathrm{ft}$} & \multicolumn{6}{|c|}{$\mathrm{h}=400 \mathrm{ft}$} \\
\hline & \multicolumn{2}{|c|}{$\mathrm{K}_{\mathrm{V}} / \mathrm{K}_{H}=0.10$} & \multicolumn{2}{|c|}{$\mathrm{K}_{\mathrm{v}} / \mathrm{K}_{\mathrm{H}}=0.60$} & \multicolumn{2}{|c|}{$\mathrm{K}_{\mathrm{V}} / \mathrm{K}_{\mathrm{H}}=1.00$} & \multicolumn{2}{|c|}{$\mathrm{K}_{\mathrm{V}} / \mathrm{K}_{\mathrm{H}}=0.10$} & \multicolumn{2}{|c|}{$\mathrm{K}_{\mathrm{v}} / \mathrm{K}_{\mathrm{H}}=0.60$} & \multicolumn{2}{|c|}{$\mathrm{K}_{\mathrm{v}} / \mathrm{K}_{\mathrm{H}}=1.00$} & \multicolumn{2}{|c|}{$\mathrm{K}_{\mathrm{v}} / \mathrm{K}_{H}=0.10$} & \multicolumn{2}{|c|}{$\mathrm{K}_{\mathrm{v}} / \mathrm{K}_{\mathrm{H}}=0.60$} & \multicolumn{2}{|c|}{$\mathrm{K}_{\mathrm{v}} / \mathrm{K}_{H}=1.00$} \\
\hline & $P_{D}$ & P'D & $P_{D}$ & $P_{D}^{\prime}$ & $P_{D}$ & $P_{D}^{\prime}$ & $P_{D}$ & $P_{D}^{\prime}$ & $P_{D}$ & $P_{D}^{\prime}$ & $P_{D}$ & $P_{D}^{\prime}$ & $P_{D}$ & $P_{D}^{\prime}$ & $P_{D}$ & $P_{D}^{\prime}$ & $P_{D}$ & P'D \\
\hline $0^{-3}$ & 0.00 & 0.28 & 0.00 & 0.15 & 0.00 & 0.14 & 0.00 & 0.68 & 0.00 & 0.31 & 0.00 & 0.26 & 0.00 & 1.08 & 0.00 & 0.48 & 0.00 & 0.39 \\
\hline $0-2$ & 0.07 & 0.32 & 0.18 & 0.25 & 0.23 & 0.26 & 0.00 & 0.72 & 0.00 & 0.41 & 0.00 & 0.39 & 0.00 & 1.12 & 0.00 & 0.57 & 0.00 & 0.51 \\
\hline $0^{-1}$ & 0.29 & 0.44 & 0.69 & 0.54 & 0.90 & 0.64 & 0.22 & 0.84 & 0.53 & 0.71 & 0.69 & 0.77 & 0.24 & 1.24 & 0.35 & 0.87 & 0.42 & 0.89 \\
\hline $0^{0}$ & 0.92 & 0.82 & 2.26 & 1.48 & 2.92 & 1.86 & 0.89 & 1.22 & 2.19 & 1.64 & 2.83 & 1.98 & 0.96 & 1.68 & 2.11 & 1.81 & 2.70 & 2.11 \\
\hline $10^{1}$ & 2.92 & 2.04 & 7.16 & 4.45 & 9.25 & 5.69 & 2.92 & 2.43 & 7.14 & 4.61 & 9.22 & 5.81 & 3.01 & 2.84 & 7.14 & 4.77 & 9.20 & 5.94 \\
\hline $10^{2}$ & 9.25 & 5.87 & 22.70 & 13.80 & 29.30 & 17.80 & 9.25 & 6.26 & 22.70 & 14.00 & 29.20 & 17.90 & 9.36 & 6.67 & 22.70 & 14.20 & 29.30 & 18.10 \\
\hline $10^{3}$ & 29.30 & 18.00 & 71.70 & 43.50 & 92.50 & 56.10 & 29.30 & 18.40 & 71.70 & 43.70 & 92.50 & 56.30 & 29.40 & 18.80 & 71.70 & 43.80 & 92.50 & 56.40 \\
\hline
\end{tabular}

Table 4: Computed Values of $P_{D T}$ and $P_{D T}^{\prime}$ for $L=2500 \mathrm{ft}$.

\begin{tabular}{|c|c|c|c|c|c|c|c|c|c|c|c|c|c|c|c|c|c|c|}
\hline \multirow[t]{3}{*}{ tD1 } & \multicolumn{6}{|c|}{$h=100 \mathrm{ft}$} & \multicolumn{6}{|c|}{$\mathrm{h}=250 \mathrm{ft}$} & \multicolumn{6}{|c|}{$\mathrm{h}=400 \mathrm{ft}$} \\
\hline & \multicolumn{2}{|c|}{$\overline{\mathrm{K}_{\mathrm{V}} / \mathrm{K}_{\mathrm{H}}=0.10}$} & \multicolumn{2}{|c|}{$\mathrm{K}_{\mathrm{v}} / \mathrm{K}_{\mathrm{H}}=0.60$} & \multicolumn{2}{|c|}{$\mathrm{K}_{\mathrm{v}} / \mathrm{K}_{\mathrm{H}}=1.00$} & \multicolumn{2}{|c|}{$\mathrm{K}_{\mathrm{V}} / \mathrm{K}_{\mathrm{H}}=0.10$} & \multicolumn{2}{|c|}{$\mathrm{K}_{\mathrm{V}} / \mathrm{K}_{\mathrm{H}}=0.60$} & \multicolumn{2}{|c|}{$\mathrm{K}_{\mathrm{v}} / \mathrm{K}_{\mathrm{H}}=1.00$} & \multicolumn{2}{|c|}{$\mathrm{K}_{\mathrm{v}} / \mathrm{K}_{\mathrm{H}}=0.10$} & \multicolumn{2}{|c|}{$\mathrm{K}_{\mathrm{v}} / \mathrm{K}_{\mathrm{H}}=0.60$} & \multicolumn{2}{|c|}{$\mathrm{K}_{\mathrm{v}} / \mathrm{K}_{H}=1.00$} \\
\hline & $\overline{P_{D}}$ & $P_{D}^{\prime}$ & $\mathrm{PD}_{\mathrm{D}}$ & $P_{D}^{\prime}$ & $\mathrm{PD}_{\mathrm{D}}$ & $P_{D}^{\prime}$ & $\mathrm{PD}_{\mathrm{D}}$ & $P_{D}^{\prime}$ & $P_{D}$ & $P_{D}^{\prime}$ & $\mathrm{PD}_{\mathrm{D}}$ & $P^{\prime} D$ & $P_{D}$ & $P_{D}^{\prime}$ & $\mathrm{PD}_{\mathrm{D}}$ & $P_{D}^{\prime}$ & $\mathrm{PD}_{\mathrm{D}}$ & $P_{D}^{\prime}$ \\
\hline $0^{-3}$ & 0.02 & 0.14 & 0.04 & 0.10 & 0.05 & 0.10 & 0.00 & 0.33 & 0.00 & 0.17 & 0.00 & 0.16 & 0.00 & 0.52 & 0.00 & 0.25 & 0.00 & 0.22 \\
\hline $10^{-2}$ & 0.09 & 0.18 & 0.21 & 0.19 & 0.27 & 0.22 & 0.05 & 0.37 & 0.12 & 0.27 & 0.15 & 0.28 & 0.00 & 0.56 & 0.00 & 0.34 & 0.00 & 0.34 \\
\hline $0^{-1}$ & 0.29 & 0.30 & 0.71 & 0.49 & 0.92 & 0.60 & 0.27 & 0.49 & 0.67 & 0.56 & 0.86 & 0.66 & 0.24 & 0.68 & 0.58 & 0.64 & 0.75 & 0.72 \\
\hline 100 & 0.93 & 0.69 & 2.26 & 1.42 & 2.92 & 1.81 & 0.92 & 0.88 & 2.25 & 1.50 & 2.90 & 1.87 & 0.91 & 1.07 & 2.22 & 1.58 & 2.86 & 1.93 \\
\hline $10^{1}$ & 2.93 & 1.90 & 7.17 & 4.39 & 9.25 & 5.64 & 2.92 & 2.09 & 7.16 & 4.47 & 9.25 & 5.71 & 2.92 & 2.28 & 7.15 & 4.55 & 9.23 & 5.76 \\
\hline $10^{2}$ & 9.25 & 5.73 & 22.70 & 13.80 & 29.30 & 17.80 & 9.25 & 5.92 & 22.70 & 13.90 & 29.30 & 17.80 & 9.25 & 6.11 & 22.70 & 13.90 & 29.30 & 17.90 \\
\hline $10^{3}$ & 29.30 & 17.90 & 71.70 & 43.50 & 92.50 & 56.10 & 29.30 & 18.00 & 71.70 & 43.50 & 92.50 & 56.10 & 29.30 & 18.20 & 71.70 & 43.60 & 92.50 & 56.20 \\
\hline
\end{tabular}

\section{RESULTS AND DISCUSSIONS}

Under this section, the result of the combination of the data selected for case study and the pressure performance equation of the horizontal well model as computed in tables $1-4$ is used to analyze the influence of the following well and reservoir parameters on the transient behaviour of reservoir system. 


\subsection{Effect of LD on Pressure Transient Behaviour of the Horizontal Well}

It is can be deduced from table 1 that as the value of $L_{D}$ increases relative to reservoir thickness, the effect of early radial flow is shortened. This implies that the quality of data derived from investigating pressure transient of shorter well lengths is usually sufficiently accurate and more reliable for near wellbore characterization.

\subsection{Effect of ho on Pressure Transient Behaviour of the Horizontal Well}

By the definition of $h_{D}$ in eqn. (22), it can be stated that an inverse relationship exists between dimensionless pay thickness of the reservoir and the dimensionless well length during the infinite-acting flow period. As evident in tables 2-4, smaller pressure drops are recorded for thicker reservoirs relative to the wellbore lengths. Also, the effect of vertical radial flow is prolonged.

\subsection{Effect of Anisotropic Ratio on the Pressure Transient Behaviour of the Well}

Anisotropy also greatly plays a major role on flow behaviour. From the tables generated, high vertical permeability shortens the effect of the early radial flow. Consequently, the production potential of the horizontal well is reduced.

\subsection{Effect of $r_{w D}$ on Pressure Transient Behaviour of the Horizontal Well}

The influence of $r_{w D}$ on pressure transient of the well model can only be felt during the infinite-acting flow stage as shown in eqn. (16). Therefore, selecting arbitrary values of $r_{w D}$ of $0.0001,0.001$ and 0.01 for an isotropic reservoir, it is revealed in table 5 that wellbores with smaller wellbore radius records better drawdown during production.

\subsection{Effect of $X_{D}$ on Pressure Transient Behaviour of the Horizontal Well}

Also observed from the investigation of the effect of $X_{D}$ on $P_{D}$ in table 6 was that as the value of $X_{D}$ increased for corresponding lengths and thicknesses, the value of $P_{D}$ reduces implying small drawdown, $\Delta P$. As a result, when pressure drawdown is large for a producing well, one is expected to record better production and vice versa; that is, it can be stated that horizontal wellbore exhibiting a uniform flux flow $\left(X_{D}=0.5\right)$ flow is expected to produce better than an infinite-conductivity well $\left(X_{D}=0.732\right)$.

\section{CONCLUSION}

Results obtained from the mathematical pressure distribution equation of the horizontal well model lead to the following conclusions:

1. A maximum of two flow periods exist (early radial and early linear flow) for the assumed horizontal well model.

2. It was deduced that solution to dimensionless pressure equation of early radial flow period of the well model is strictly a function of dimensionless time while the intermediate linear flow period is majorly influenced by high vertical permeability.

Table 5: Computed Values of $P_{D}$ for Varying Values of Dimensionless Wellbore Radius

\begin{tabular}{cccccccccc}
\hline & \multicolumn{3}{c}{$\mathrm{P}_{\mathrm{D}}$} & \multicolumn{3}{c}{$\mathrm{PD}_{\mathrm{DD}}$} & \multicolumn{3}{c}{$\mathrm{h}=100 \mathrm{ft}$} \\
\cline { 2 - 11 } & $\mathrm{L}=800 \mathrm{ft}$ & $\mathrm{L}=1200 \mathrm{ft}$ & $\mathrm{L}=2500 \mathrm{ft}$ & $\mathrm{L}=800 \mathrm{ft}$ & $\mathrm{L}=1200 \mathrm{ft}$ & $\mathrm{L}=2500 \mathrm{ft}$ & $\mathrm{L}=800 \mathrm{ft}$ & $\mathrm{L}=1200 \mathrm{ft}$ & $\mathrm{L}=2500 \mathrm{ft}$ \\
\hline 0.0001 & 3.14 & 2.13 & 1.09 & 7.08 & 4.88 & 2.49 & 10.79 & 7.46 & 3.81 \\
0.001 & 2.56 & 1.78 & 0.91 & 5.64 & 3.93 & 2.03 & 8.48 & 5.92 & 3.08 \\
0.01 & 1.99 & 1.40 & 0.73 & 4.19 & 2.97 & 1.57 & 6.18 & 4.39 & 2.34 \\
\hline
\end{tabular}

Table 6: Computed Values of $P_{D}$ for Varying Values of $X_{D}$ for an Isotropic Reservoir

\begin{tabular}{|c|c|c|c|c|c|c|c|c|c|}
\hline \multirow{3}{*}{$X_{D}$} & \multicolumn{3}{|c|}{ PD } & \multicolumn{3}{|c|}{$P D$} & \multicolumn{3}{|c|}{$P_{D}$} \\
\hline & \multicolumn{3}{|c|}{$\mathrm{h}=100 \mathrm{ft}$} & \multicolumn{3}{|c|}{$\mathrm{h}=250 \mathrm{ft}$} & \multicolumn{3}{|c|}{$\mathrm{h}=400 \mathrm{ft}$} \\
\hline & $\mathrm{L}=800 \mathrm{ft}$ & $\mathrm{L}=1200 \mathrm{ft}$ & $\mathrm{L}=2500 \mathrm{ft}$ & $\mathrm{L}=800 \mathrm{ft}$ & $\mathrm{L}=1200 \mathrm{ft}$ & $\mathrm{L}=2500 \mathrm{ft}$ & $\mathrm{L}=800 \mathrm{ft}$ & $\mathrm{L}=1200 \mathrm{ft}$ & $\mathrm{L}=2500 \mathrm{ft}$ \\
\hline 0.2 & 0.51 & 0.53 & 0.54 & 0.31 & 0.42 & 0.50 & 0.13 & 0.26 & 0.45 \\
\hline 0.4 & 0.49 & 0.52 & 0.53 & 0.28 & 0.39 & 0.48 & 0.11 & 0.25 & 0.44 \\
\hline 0.6 & 0.45 & 0.47 & 0.48 & 0.25 & 0.36 & 0.44 & 0.11 & 0.21 & 0.39 \\
\hline
\end{tabular}


3. The wellbore length has no significant effect on the pressure behavior of horizontal wells at early time.

4. When the flow reaches upper and lower impermeable boundaries of the formation, the fluid streamlines begins to straighten and the well begins to experience early linear flow.

5. Longer wellbore length gives lesser productivity index than short well lengths; also reservoirs with lesser $\mathrm{K}_{\mathrm{v}} / \mathrm{K}_{\mathrm{H}}$ ratio record better productivity index than those with higher values.

6. Shorter perforation lengths $\left(X_{D}\right)$ of horizontal wells produce better due to increased pressure drawdown.

\section{NOMENCLATURE}

$B=$ oil formation volume factor, $r b b l / S T B$

$E_{i}=$ exponential integral

$\mathrm{C}_{\mathrm{t}}=$ rock compressibility, $\mathrm{psi}^{-1}$

$\mathrm{h}=$ reservoir pay thickness, $\mathrm{ft}$

$\mathrm{h}_{\mathrm{D}}=\mathrm{Z}_{\mathrm{eD}}=$ dimensionless reservoir thickness

$\mathrm{k}_{\mathrm{x}}, \mathrm{k}_{\mathrm{y}}, \mathrm{k}_{\mathrm{z}}=$ permeability in the $\mathrm{x}, \mathrm{y}, \mathrm{z}$ direction respectively, md

$\mathrm{k}_{\mathrm{H}}=$ effective horizontal permeability in the areal plane or it is also referred to as the permeability parallel to the bedding plane and it is of great interest, $\mathrm{md}$

$\mathrm{k}_{\mathrm{v}}=$ effective vertical permeability in the areal plane. It is the permeability in the direction perpendicular to the bedding which controls flow due to gravity, md $\mathrm{L}=$ horizontal well length $\mathrm{ft}$

$L_{D}=$ dimensionless well length

$\mathrm{P}_{\mathrm{D}}($ dimensionless pressure $)=\frac{\mathrm{k}_{\mathrm{H}} \mathrm{h}\left(\mathrm{P}_{\mathrm{i}}-\mathrm{P}_{\mathrm{wf}}\right)}{141.2 \mathrm{q} \mu \mathrm{B}}$

$\mathrm{P}_{\mathrm{D}}^{\prime}=$ dimensionless pressure derivative

$\mathrm{P}_{\mathrm{i}}=$ initial reservoir pressure, $\mathrm{psi}$

$\mathrm{P}_{\mathrm{wf}}=$ flowing bottom hole pressure, $\mathrm{psi}$

$\mathrm{q}=$ flow rate, $\mathrm{STB} / \mathrm{D}$

$r_{w}=$ wellbore radius, $\mathrm{ft}$

$r_{W D}=$ dimensionless wellbore radius

$\mathrm{S}=$ skin factor

$\mathrm{t}=$ flow time, hrs

$\mathrm{t}_{\mathrm{D}}($ dimensionless time $)=\frac{0.001055 \mathrm{k}_{\mathrm{H}} \mathrm{t}}{\emptyset \mu \mathrm{c}_{\mathrm{t}} \mathrm{L}^{2}}$

$t_{e}=$ time taken for flow to reach the boundaries in the vertical plane, hrs

$t_{D e}=$ dimensionless time taken for flow to reach the boundaries in the vertical plane

$\mathrm{X}_{\mathrm{D}}=$ perforation length
$\mathrm{ZD}=$ dimensionless distance from reservoir bottom to centre of the well

$\mathrm{Z}_{\mathrm{wD}}=$ dimensionless distance from reservoir bottom to well bottom

$\mu=$ fluid viscosity, $\mathrm{cp}$

$\varnothing=$ porosity

$\Delta \mathrm{P}($ drawdown $)=\mathrm{P}_{\mathrm{i}}-\mathrm{P}_{\mathrm{wf}}$

\section{REFERENCES}

[1]. Carslaw, H.S. and Jaeger, J.C. Conduction of Heat in Solid (Second Edition), Oxford Clarendon Press, Oxford, 1959.

[2]. Joshi, S.D. Horizontal Well Technology, Pennwell Books, Pennwell Publishing Company Tulsa, Oklahoma, 1991.

[3]. Gringarten, A.C and Ramey, H.J. "The use of Source and Green's Function in Solving Unsteady State Flow Problems in Reservoir", Society of Petroleum Engineering Journal, 1973, pp 285-295.

[4]. Odeh, A.S and Babu, D.K. "Transient Flow Behaviour of Horizontal Well Pressure Drawdown and Buildup Analysis", SPE Formation Evaluation, 1990, pp 7-15.

[5]. Chukwuma, M.S and Adewole, E.S. "Application of Odeh and Babu Strategies for Determination of Flow Periods in a Horizontal Well in a Bounded Reservoir", Journal of the Nigerian Association of Mathematical Physics, Vol. 39, 2017, pp 245-248.

[6]. Yasin, I.B.E. "Pressure Transient Analysis Using Generated Well Test Data from Simulation of Selected Wells in Norne Field www.4shared.com, Accessed on May 9, 2017.

[7]. Rbeawi, S.A and Tiab, D. "Transient Pressure Analysis of Horizontal in a MultiBoundary System", American Journal of Engineering Research, Vol. 2, Issue 04, 2013, pp 44-66.

[8]. Adewole E.S, Rai B.M and Audu T.O.K. "The Use of Gauss-Legendre Quadrature in Solving Flow Problems in Reservoirs Containing Horizontal Wells", Journal of the Nigerian Association of Mathematical Physics, Vol. 5, 2001, pp 89-100.

[9]. Earlougher, R.C. Jr. Advances in Well Test Analysis, Monograph Series, SPE, Dallas 1977.

[10]. Carnaham B, Luther H.A and Wilkes J.O. Applied Numerical Methods, John Wiley and Sons Inc, New York, 1969.

[11]. Chaudhri, A.U. Oil Well Testing Handbook. Gulf Professional Publishing Burlington, USA, 2004. 